\title{
REVISITANDO OS ESTUDOS E EVENTOS SOBRE A FORMAÇÃO DO NUTRICIONISTA NO BRASIL 1
}

\section{REVISITING THE STUDIES AND EVENTS ON THE FORMATION OF NUTRI- TIONISTS IN BRAZIL}

Nilce Maria da Silva Campos $\operatorname{COSTA}^{2}$

RESUMO

Relata a formação do nutricionista no Brasil, a partir de uma retrospectiva histórica dos eventos e estudos brasileiros e latino-americanos em que ocorreram debates/discussões sobre a formação desse profissional. Parte-se de um breve histórico sobre a formação do nutricionista inserida na formação de profissionais para o mercado de trabalho em saúde, uma etapa da formação do mercado capitalista de um modo geral. Em seguida é realizada uma revisão dos eventos e estudos que se dedicaram ao tema, através da qual pode-se perceber a presença de momentos característicos, assim como de eixos temáticos que os permeiam. $O$ artigo termina com a reflexão sobre o significado dos estudos e eventos já realizados sobre a formação do nutricionista no contexto dos profissionais da área da saúde no momento atual.

Termos de indexação: nutricionista, formação profissional, perfil profissional, curriculum.

\begin{abstract}
This article discourses upon the formation of nutritionists in Brazil, through a historical retrospective of Brazilian and Latin-American events and studies in which debates/ discussions about the formation of this professional occurred. The first part of the article is dedicated to the historical formation of nutritionists, which is inserted in the formation of professionals for the health work market, in general, also a part of the formation of a capitalist market. Afterwards, a review of the events and studies about the theme was made, through which was possible to perceive the presence of characteristic moments as well as thematic issues among them. The article ends with a discussion of the insertion of nutritionists in a wider context of health professionals in the present moment of capitalist society.
\end{abstract}

Index terms: nutritionist, professional formation, professional profile, curriculum.

(1) Texto baseado no capítulo "Revisitando a formação do nutricionista" da dissertação de mestrado "Currículo e formação profissional: as reformulações curriculares dos cursos de Nutrição", apresentada à Faculdade de Educação da Universidade Federal de Goiás, em dezembro de 1996.

(2) Faculdade de Nutrição, Universidade Federal de Goiás, Rua 227, Quadra 68, Setor Leste Universitário, 74605-080, Goiânia, Goiás. 
INTRODUÇÃO

A formação do nutricionista vem sendo discutida na América Latina em eventos científicos envolvendo especialistas e profissionais da área de Nutrição desde a década de sessenta ${ }^{3}$, a partir da qual tem ocorrido uma significativa expansão dos cursos de Nutrição latino-americanos.

No Brasil, a formação em Nutrição tem sido alvo de preocupação não apenas das instituições formadoras, como também de outras instituições governamentais e dos órgãos representativos da categoria, principalmente da entidade de representação profissional dos nutricionistas, a Associação Brasileira de Nutrição (ASBRAN) ${ }^{4}$, que no decorrer das últimas décadas tem realizado eventos e estudos acerca da formação acadêmica do nutricionista (Brasil..., 1983; Federação..., 1989; Associação..., 1992).

A compreensão da formação do nutricionista, enquanto prática social desenvolvida numa realidade concreta e histórica, entretanto, é obtida ao se responder à pergunta: que condições materiais permitiram o desenvolvimento do profissional nutricionista no Brasil? Assim, a formação profissional deve ser analisada como parte integrante da prática produtiva capitalista, através do resgate histórico da formação, inserida no contexto da estrutura socioeconômica brasileira, pois a pergunta: "para que formar nutricionistas?", está ligada a uma outra: "qual a razão social dessa formação?"

A partir da bibliografia nacional concernente ao profissional nutricionista, verifica-se a existência de trabalhos desenvolvidos nas décadas de oitenta e noventa que recuperam a trajetória da formação e da prática desse profissional, dentro de uma abordagem histórico-social, ou seja, no contexto do processo de constituição da sociedade capitalista brasileira. Constata-se, através deles, que a prática do nutricionista assim como o currículo dos cursos de Nutrição têm contribuído para a manutenção das relações sociais vigentes (Bosi, 1988; Santos, 1988; Barreto, 1992).

A evolução na reflexão acerca desse profissional continua na década de noventa, com a publicação de artigos e a realização de estudos nos quais ocorrem o aprofundamento da discussão em torno de objetos mais específicos, como por exemplo, as proposições teóricas debatidas pelos nutricionistas (Nunes, 1992) e as representações sociais que trazem sobre a sua prática (Prado, 1993). Além deles, livros publicados assinalam questões primordiais para a compreensão dessa profissão no mundo contemporâneo, como o de Bosi (1996), que discute a identidade e a profissionalização dos nutricionistas, e o de Viana (1996), que estuda a prática desenvolvida pelos nutricionistas na área de Alimentação Institucional, na tentativa de apreender o significado social dessa prática.

Considerando a influência que os eventos e estudos realizados com o objetivo de discutir a formação do nutricionista tem exercido nos cursos de graduação que formam nutricionistas para a sociedade brasileira, este artigo propõe-se a estudar a formação em Nutrição a partir dos eventos e estudos latino-americanos, patrocinados pela Organização Panamericana da Saúde e Organização Mundial da Saúde (OPS/OMS) com influência destacada na formação do nutricionista no Brasil e dos estudos e eventos brasileiros, realizados por iniciativa das entidades de representação profissional da categoria dos nutricionistas, com o propósito explícito de discussão dessa temática.

Inicialmente parte-se de um breve histórico sobre a formação do nutricionista inserida na formação de profissionais para o mercado de trabalho em saúde, para em seguida proceder-se a uma revisita aos estudos e eventos sobre a formação do nutricionista, quando ocorreram o debate e a formulação de propostas visando ao aprimoramento da formação profissional, os quais resultaram em recomendações utilizadas para a organização dos currículos dos cursos de Nutrição.

\section{HISTÓRICO}

A formação do nutricionista confunde-se com a formação de profissionais para o mercado de trabalho em saúde, constituindo uma etapa da formação do mercado capitalista de um modo geral. O processo de

\footnotetext{
(3) Esses encontros têm contado com o apoio da Organização Panamericana da Saúde (OPS/OMS) que desde 1940 colabora técnica e financeiramente com a realização de eventos sobre a formação do nutricionista, com o propósito de definir o papel desse profissional e homologar o currículo dos programas de formação (Organización..., 1977).

(4) Essa entidade foi criada oficialmente em 1972, como Federação Brasileira de Nutrição (FEBRAN), herdeira do caráter nacional que a Associação Brasileira de Nutricionistas (ABN), primeira entidade a congregar nutricionistas no Brasil, vinha tentando cumprir. Posteriormente, em 1990, durante a XVI Assembléia Geral Ordinária dos Delegados da FEBRAN, sua denominação foi mudada para ASBRAN, devido à necessidade de adequação legal às entidades da sociedade civil (Associação..., 1991).
} 
formação desse mercado de trabalho, ou seja, a perspectiva da saúde enquanto "mercadoria", tem início com o nascimento da ordem econômica capitalista, "y obtiene su configuración definitiva en el siglo XX, cuando el Estado y el capital, en el sector, pasan a influir de forma más decisiva en la determinación del precio y en las relaciones de compra y venta de esa fuerza de trabajo" (Medici et al., 1991).

Com o desenvolvimento do capitalismo na América Latina, a partir da década de trinta e nas duas seguintes, surgiu também a capitalização do setor saúde, que definiu a necessidade da especialização na formação profissional. A especialização em saúde tem sido um dos traços comuns no cenário histórico dos países com expressivo desenvolvimento socioeconômico ao longo deste século (Santana \& Girardi, 1993). Como consequiência das transformações na divisão técnica do trabalho em saúde, surgiram novos profissionais na área, entre eles, o nutricionista, cujos primeiros passos giraram em torno do desenvolvimento da prática hospitalar de assistência ao paciente.

As décadas de trinta a cinqüenta caracterizaramse pelo fortalecimento da atenção médica, constituindo o hospital o espaço privilegiado para esse tipo de atenção. Essa etapa foi a do desenvolvimento da medicina estatal e da incorporação da assistência médica como contribuição do Estado para o cuidado da enfermidade individual (Infante, 1992). As condições históricas para o surgimento do profissional nutricionista apareceram, portanto, dentro do setor saúde, como divisão técnica do trabalho no setor, que até então concentrava no médico a responsabilidade da atenção ao paciente.

Essa divisão técnica, entretanto, constituía também uma divisão social do trabalho em saúde, evidenciada pelo modo como se articulava nesse período a prática do nutricionista no contexto da estrutura social latino-americana, caracterizada pela subordinação frente aos profissionais da medicina. Confirmava-se, portanto, que as divisões técnica e social do trabalho em saúde são construídas institucionalmente a partir de determinantes históricosociais (Castellanos et al., 1992). A prática do nutricionista, na sua origem, estava ligada à prática médica nos hospitais, exercida na área clínica, sem participação na promoção da saúde e tampouco na sua prevenção. Prática individual, curativa e hospitalar, pois o enfoque clínico orienta as ações para esse tipo de atenção. O trabalho do nutricionista era utilizado de forma complementar ao ato médico e a ele encontrava-se subordinada.

O primeiro curso de formação de dietistas na América Latina, surgiu na Argentina, em 1926, quando o professor Pedro Escudero criou a Escola Municipal de Dietistas, que conquistou o nível universitário em 1939. No Brasil, a origem da profissão ocorreu na região Sudeste, mais precisamente nas cidades de São Paulo e na então capital do país, Rio de Janeiro (Associação..., 1991).

O nutricionista surgiu no Brasil como dietista, dentro de uma equipe técnica individualista, com a responsabilidade de prestar assistência ao paciente, através da alimentação. Santos (1988) assinala que o dietista era um profissional de nível médio, cuja formação e campo de prática eram pré-definidos pelos ideólogos da problemática alimentar brasileira da época, os médicos nutrólogos: "o dietista pode ser compreendido como uma função que [...] passou a constituir mais um agente de saúde, trazendo já em sua origem histórica as determinações de uma prática complementar ao ato médico e a este subordinada técnica e financeiramente".

A relação hegemônica da medicina - profissão dominante na área da saúde - com as demais profissões da área tem sido discutida em alguns estudos, que evidenciam a relação hierarquizada existente entre os profissionais de nutrição e os médicos nutrólogos, recuperando o caráter de subordinação e os mecanismos de resistência utilizados pelos primeiros (Santos, 1988; Nunes, 1992). Para Castellanos et al. (1992), a medicina detém o domínio do trabalho intelectual na área da saúde e com isso o controle da assistência ao paciente, reproduzindo "as relações de classe da sociedade brasileira, estabelecendo com as demais profissões do setor saúde relações de poder para a sua própria reprodução".

Segundo Bazó (1977), a partir da década de cinqüenta, o dietista na América Latina passou a ser designado de nutricionista-dietista, como uma adaptação da terminologia usada nos Estados Unidos da América do Norte (EUA), país em que eram formados os dois profissionais, o dietista e o nutricionista, com funções independentes e bem delimitadas.

O Brasil, entretanto, adotou a denominação "nutricionista", diferentemente do ocorrido nos demais 
países latino-americanos, conforme mostram Ypiranga \& GIL, (1989): “No Brasil, rejeitou-se porémeste conceito e o termo Dietista designa um técnico de nível médio ou auxiliar de Nutrição. Esta decisão ficou oficializada internacionalmente, em 1966, em Caracas".

$\mathrm{Na}$ América Latina até a década de sessenta, os esforços de formação de nutricionistas concentraram-se na preparação de dietistas para trabalhar em instituições hospitalares (Ariza, 1992). No Brasil, por outro lado, além dessa prática hegemônica, a profissão teve raízes na fase em que o modelo capitalista de produção se vinculava à política populista da década de quarenta, em que se originou a preocupação nacionalista por parte do Estado, como forma de embasamento social para sua manutenção no poder (Santos, 1988) $)^{5}$.

Nesse contexto, despontava no país uma política social extremamente marcada pelo assistencialismo, período em que surgiram os cursos de Nutrição. A necessidade de implementação da formação de recursos humanos nessa área ligava-se, portanto, à política assistencialista-populista assumida pelo Estado. Os nutricionistas, administrando a alimentação para o trabalhador, constituíam-se, então, em mais um instrumento de alívio de tensões sociais (Ypiranga \& Gil, 1989).

A institucionalização do nutricionista relacionava-se, portanto, às políticas de prestação de serviços assistenciais patrocinados pelo Estado, que desenvolvia essa prática a partir dos órgãos públicos de saúde criados na década de quarenta. Entre eles, destacava-se o Serviço de Alimentação e Previdência Social (SAPS) criado no Rio de Janeiro, pelo decreto presidencial $n^{\circ} 2.478$ de 5/8/1940, órgão destinado à execução de parte da política social do Estado, vinculado ao Ministério do Trabalho, Indústria e Comércio, primeiro órgão de política de Alimentação instituído pelo Estado Brasileiro, auxiliar da política trabalhista de Getúlio Vargas, como um dos meios de sustentação do seu governo. A função explícita daquele órgão era a de assegurar condições favoráveis e higiênicas à alimentação dos segurados dos Institutos de Aposentadorias e Pensões, subordinados ao ministério ao qual se vinculavam. De acordo com L'Abbate (1988), colaborava, portanto, para minimizar possíveis tensões sociais, indesejáveis no momento em que se deveria concentrar todos os esforços "na construção de um sistema econômico de base capitalista industrial sob vigência da ideologia nacionalistai".

No SAPS, as funções diretivas eram exercidas por médicos nutrólogos, os quais, sentindo a necessidade de contar com pessoal especializado para a execução das atividades do setor, criaram cursos para a formação técnica desse pessoal, como os profissionais de copa, cozinha e atividades afins ligadas à alimentação, entre eles, o dietista.

A experiência do SAPS como instituição formadora teve início em 1943, com o curso de auxiliares técnicos em alimentação, com a duração de um ano. Posteriormente, passou a contar com o curso de dois anos, que formava dietistas e mais tarde com o de três anos, para formação de nutricionistas (Santos, 1988).

A política de Nutrição do Estado Novo visava, acima de tudo, a transformar a alimentação em um instrumento eficaz de manipulação das classes subalternas. O Estado, ao assumir a alimentação do trabalhador, procurava, na verdade, atender aos interesses e necessidades das empresas privadas. Nesse período, deu-se a expansão da indústria de alimentos em consonância com o Estado, que criou outros órgãos públicos como o Serviço Técnico de Alimentação Nacional, em 1942, e o Instituto de Tecnologia Alimentar, em 1944, iniciando a colaboração entre Estado e indústria de alimentos, com apoio a concessões de prioridades, subvenções e isenções fiscais, consideradas indispensáveis para o desenvolvimento daquelas indústrias, atividade econômica fundamental para a acumulação de capital (L'Abbate, 1988).

Os programas de alimentação do governo inseriam-se, assim, dentro da nova configuração da sociedade de classes, reproduzindo a estrutura econômica capitalista em consolidação, porém camuflada através de uma ideologia paternalista: a alimentação oferecida ao trabalhador, aos menos favorecidos, aparentava ter caráter de prêmio, criando a possibilidade de extrair parcela maior de "maisvalia" dos trabalhadores melhor alimentados. OEstado criava e financiava as condições para a exploração do trabalhador (L'Abbate, 1988).

Após os passos iniciais da formação do profissional nutricionista, então dietista, foram criados

(5) Ver Santos (1988), p.40-45, sobre a análise das pré-condições políticas para a emergência do profissional nutricionista no Brasil. 
os cursos de nível universitário da Universidade de São Paulo (USP), Universidade do Rio de Janeiro (UNIRIO) ${ }^{6}$ e da Universidade Estadual do Rio de Janeiro (UERJ) ${ }^{7}$, na década de quarenta, seguidos pelos da Universidade Federal da Bahia (UFBA) em 1956, e Universidade Federal de Pernambuco (UFPE) em 1957. O curso da Universidade Federal Fluminense (UFF) foi criado em 1967.

As décadas de cinqüenta e sessenta caracterizaram-se pelo grande desenvolvimento industrial no Brasil, através da desnacionalização da economia, com grandes vantagens ao capital estrangeiro. Nessa época, estabeleceu-se a relação entre saúde e desenvolvimento. $\mathrm{O}$ desenvolvimentismo acarretou o aumento das desigualdades sociais, e o golpe de 1964 representou, na verdade, o golpe nas aspirações populares que implicavam a luta pelas transformações socioeconômicas do país. Ocorreu, então, a tomada do poder pelos interesses multinacionais e a instauração de uma nova ordem política de base ditatorial, com a instituição da democracia excludente.

Nesse período a profissão era tida como exclusivamente feminina, conforme atestam documentos que divulgavam a profissão como um "novo campo profissional e de magníficas oportunidades aberto às moças deste país" (grifo meu). A profissão era vista também como "jovem e promissora" (grifo meu), pelo surgimento da preocupação com o problema alimentar e nutricional da população brasileira e pela emergência da "medicina comunitária", que utilizava o trabalho de outras categorias profissionais como complementares ao ato médico. A educação alimentar era considerada, então, como a ferramenta necessária para "libertar a sociedade humana da doença e da fome" (Santos, 1988).

A formação do nutricionista manteve-se restrita, com apenas sete cursos, até a década de setenta, quando ocorreu o explosivo aumento do ensino superior no país, a partir da Reforma Universitária instituída pela lei 5.540 de 1968, a qual incrementou a formação profissional em todos os cursos da área de saúde.
Houve, então, uma formação maciça de nutricionistas a partir da década de setenta, comparada com as décadas anteriores, principalmente com o crescimento das instituições privadas de ensino superior. Essa foi uma tendência observada não apenas nos cursos de Nutrição: "o crescimento da participação das instituições privadas de ensino na formação superior em saúde no Brasil apresenta uma tendência constante e ascendente [...] enquanto que no setor público [...] esta proporção tende a cair, especialmente nas instituições municipais", (grifo meu) (Brasil..., 1993).

Constata-se também que a evolução do capitalismo no país influenciou o mercado de trabalho do nutricionista, acarretando modificações na formação acadêmica. Na década de oitenta, as modificações apareceram em nível teórico nas discussões nacionais sobre a formação do nutricionista, e inicialmente aparentavam um caráter de resistência a esse modo de produção: na realidade, queriam recuperar e formar um profissional que atuasse na transformação da sociedade. Por outro lado, a evolução do sistema capitalista acarretou modificações na praticidade dos currículos, que procuraram concretamente ajustá-los às oportunidades oferecidas pelo mercado de trabalho.

Essa é a contradição vivenciada pela formação em Nutrição no Brasil e uma indagação a ser respondida através da reflexão realizada a seguir sobre os estudos e eventos que discutiram a formação do nutricionista: "Qual tem sido o eixo condutor da formação do nutricionista e pode ser desvelado a partir dos estudos e eventos que se dedicaram à essa temática?"

\section{Percorrendo os estudos e eventos sobre a formação do Nutricionista}

Recuperar a formação do nutricionista requer uma retrospectiva histórica dos momentos de discussão sobre a formação desse profissional, com uma revisão teórica e bibliográfica acerca dos estudos e eventos mais significativos sobre esta temática, com o objetivo de repensá-los em função dos movimentos em que ocorreram e dos interesses a que se vincularam.

\footnotetext{
(6) A Universidade do Rio de Janeiro foi criada em 1979 e incorporou o curso do SAPS, extinto em 1967, quando o curso de nutricionistas passou a integrar a Federação das Escolas Federais do Estado da Guanabara - FEFIEG (Associação..., 1991).

(7) Em 1975, o curso de graduação de Nutricionistas do Instituto "Annes Dias" da Secretaria de Educação do antigo Estado da Guanabara, foi incorporado à Fundação Universidade Federal do Rio de Janeiro: "Neste mesmo ano foi criado o Departamento de Nutrição que passou a funcionar em caráter de emergência na Faculdade de Enfermagem da UERJ onde funcionou até 31 de outubro de 1984, data em que foi criado o Instituto de Nutrição da UERJ" (Associação..., 1991, p.56).
} 
Serão trabalhados neste artigo os eventos latino-americanos com influência destacada na formação do nutricionista no Brasil: 1) as Conferências sobre Adestramento de Nutricionistas-Dietistas de Saúde Pública, a primeira realizada em 1966, em Caracas, Venezuela, e a última em 1973, em São Paulo, Brasil; 2) as reuniões da Comissão de Estudos sobre Programas Acadêmicos em Nutrição e Dietética na América Latina (CEPANDAL), a primeira ocorrida em 1973, em Bogotá, Colômbia, a segunda em 1974, em Washington, DC, a terceira em 1977, em Brasília, Brasil, e a última em 1991, em San Juan, Porto Rico. (Associação..., 1991).

Dentre os eventos e estudos ocorridos no Brasil, ressaltam-se os realizados nas décadas de setenta e oitenta, por iniciativa da Associação Brasileira de Nutrição (ASBRAN), como o I Diagnóstico dos Cursos de Nutrição, sob os auspícios do Instituto Nacional de Alimentação e Nutrição (INAN) realizado em Garanhuns, estado de Pernambuco, em 1975; o II Diagnóstico dos Cursos de Nutrição e I Seminário Nacional de Avaliação do Ensino de Nutrição, em Brasília, em 1982, além do II Seminário Nacional Sobre o Ensino de Nutrição, em 1987, na cidade de Salvador.

Quando se realiza o aprofundamento nesses eventos e estudos, percebe-se inicialmente a existência de dois canais de discussão, independentes de espaço geográfico, porém complementares em nível de idéias. Um específico em relação ao Brasil e outro mais abrangente relativo à América Latina: apesar das especificidades, a formação do nutricionista no Brasil tem sido influenciada pelo movimento mais amplo que abrange as nações latino-americanas.

Além dos espaços diferenciados, nota-se que os eixos do debate podem ser classificados em momentos ou fases. O primeiro é o momento em que se procura delimitar as atribuições do nutricionista e estabelecer recomendações quanto ao currículo de formação. Evidencia-se nele a tentativa de traçar os contornos do profissional e da formação acadêmica de uma profissão ainda nova no cenário latino-americano. No segundo momento, busca-se a identificação, a quantificação e a discussão dos problemas existentes na formação profissional, quando ocorrem os debates acerca da formação do nutricionista. A análise dos dois mo- mentos, permite a verificação, em uma primeira aproximação, da existência de eixos temáticos comuns que os perpassam com maior ou menor intensidade: $\mathrm{o}$ perfil profissional e o currículo.

Primeiro momento:delimitação das atribuições do nutricionista e estabelecimento de recomendações curriculares

Destaca-se nesse momento, a influência de ambas as Conferências de Adestramento de Nutricionistas-Dietistas de Saúde Pública, patrocinadas pela OPS/OMS, cujas conclusões e recomendações deveriam ser adotadas pelos cursos/ escolas de Nutrição latino-americanos.

Entre os principais objetivos da I Conferência de Adestramento de Nutricionistas - Dietistas de Saúde Pública, em 1966, estavam o de delimitar as responsabilidades e qualificações do nutricionistadietista nos programas dos serviços de saúde. Naquele evento, a nutrição foi colocada como um componente básico da saúde individual, surgindo a necessidade de incorporá-la como ciência aplicada aos serviços integrados de saúde. Vigoravam, então, os conceitos sobre planejamento em saúde pública, incluindo objetivos a curto e longo prazo em relação aos programas integrados de saúde. Isso implicava a necessidade de pessoal qualificado em várias tarefas de administração sanitária e cujo desenvolvimento exigia o trabalho conjunto da equipe de saúde com experiência e capacitação em várias disciplinas (Organización..., 1977).

A ação do nutricionista, categoria profissional relativamente nova, era necessária aos programas de Nutrição em saúde, os quais estavam inseridos dentro dos serviços integrados de saúde, como uma especialização necessária a esses serviços e utilizada de forma complementar ao ato médico. Suas atividades deveriam ser exercidas nos serviços de saúde pública e em serviços de alimentação de hospitais, centros de saúde e outras instituições, para executar a administração e o tratamento dietético dos enfermos (Organización..., 1977).

Atualizar as funções do nutricionista-dietista continuou sendo um dos principais objetivos da II Conferência de Adestramento de NutricionistasDietistas de Saúde Pública, em 1973. 
No Brasil, os eventos ocorridos na época ${ }^{8}$ seguiram a tendência latino-americana. A temática discutida referia-se principalmente às questões administrativas e práticas em relação à necessidade de delimitação do espaço a ser ocupado pelo nutricionista no país. Evidenciou-se a tentativa de afirmação do profissional junto a equipes de trabalhos em Saúde Pública e o empenho em mostrar a importância e a necessidade do nutricionista, como demonstram uma série de recomendações às autoridades competentes, elaboradas na década de sessenta, por ocasião dos congressos da categoria profissional.

Segundo a Associação...(1991), no IV Congresso Brasileiro de Nutricionistas tentou-se, por exemplo, garantir ao profissional o ensino das disciplinas "comprovadamente profissionais" dos cursos de Nutrição. Em 1965, no III Congresso Brasileiro de Nutricionistas, recomendou-se que se insistisse junto às autoridades, na conveniência de os nutricionistas integrarem equipes de trabalho em Saúde Pública. Em 1967, solicitou-se às escolas e cursos de Saúde Pública que admitissem os nutricionistas entre os profissionais que neles pudessem se inscrever "de modo a que melhor se capacite para integrar a equipe de Saúde". Através dos documentos percebe-se a preocupação em buscar uma definição para uma profissão com visibilidade social baixa, carecendo de identidade própria tanto para a sociedade, quanto para a própria categoria profissional.

As recomendações para a realização de estudos acerca da definição de funções e atividades de competência e responsabilidade do nutricionistadietista continuaram nas reuniões realizadas na década de setenta, inclusive como uma das recomendações da II CEPANDAL, em 1974 (Organización..., 1977).

Quanto ao currículo para a formação de nutricionistas, também aparecem recomendações nas duas Conferências de Adestramento de Nutricionistas - Dietistas de Saúde Pública. A primeira delas, porém, é a mais significativa em relação ao ensino de Nutrição.

Na década de sessenta os currículos adotados pelos diferentes cursos apresentavam uma grande diversidade estrutural, o que ocasionou a necessidade de uniformização curricular. Na I Conferência de Adestramento em 1966, um dos objetivos foi o de estabelecer recomendações práticas para orientar a formação do nutricionista. Elas versavam sobre questões administrativas, como os requisitos mínimos para admissão no curso, a duração, o número de alunos, a qualificação do pessoal docente, os recursos materiais e institucionais necessários. Especificavam também as normas técnicas de ensino para a formação do nutricionista, com a descrição de aspectos considerados essenciais para a organização dos programas de ensino (Organizacióm..., 1977).

Naquela ocasião, ficaram definidas as cinco áreas gerais do ensino em Nutrição: Ciências Básicas, Ciências Sociais e Econômicas, Ciências Pedagógicas, Ciências da Saúde Pública e Ciências da Alimentação e Nutrição. Quanto às áreas de estudo, estabeleceramse os conteúdos e a intensidade das mesmas, ou seja, as disciplinas componentes de cada área e a contribuição de cada uma ao currículo, em relação a carga horária.

$\mathrm{Na}$ II Conferência de Adestramento de Nutricionistas-Dietistas, em 1973, uma das propostas foi a de analisar os programas dos cursos de Nutrição. Reconheceu-se que as recomendações estabelecidas na reunião anterior, em 1966, continuavam sendo um guia adequado para formação, apresentando, contudo, falhas tanto em relação ao conteúdo de cada disciplina como ao estabelecimento de critérios para o nível e a qualidade dos cursos oferecidos (Organización..., 1977).

Aprovou-se, então, a criação de uma comissão a ser responsável pelos estudos sobre o ensino de Nutrição na América Latina, que posteriormente foi denominada CEPANDAL. Sua criação objetivou: 1) definir e elaborar normas que permitissem a comparabilidade dos planos de estudo e estabelecer o conteúdo mínimo de cada disciplina e sua intensidade medida através do sistema de créditos ou pontos equivalentes;2) preparar guias para o desenvolvimento das práticas supervisionadas e para seleção de pessoal docente e 3) estabelecer as necessidades mínimas de recursos humanos, recursos materiais e de instalações físicas necessárias (Organización..., 1977).

Observou-se naquela ocasião, a ênfase dada pela OPS/OMS, a idéia da formação de pessoal de saúde como forma de reverter o grave quadro nutricional dos países da América Latina, ou seja, considerava-se

\footnotetext{
(8) Em 1965, por ocasião do "III Congresso Brasileiro de Nutricionistas e I Encontro Latino Americano de Nutricionistas", uma das áreas temáticas discutidas foi: o profissional de Nutrição: sua formação, atividades e perspectivas futuras. Em 1967, no "IV Congresso Brasileiro de Nutricionistas " o tema básico "Nutrição e Desenvolvimento" teve entre os subtemas: a formação do nutricionista em função do desenvolvimento (Associação..., 1991).
} 
como um dos fatores responsáveis pela desnutrição, o número limitado de profissionais capacitados em Nutrição (Bosley, 1977).

No Brasil, a preocupação com a formação dos nutricionistas continuou na década de setenta, com a realização em 1972, da I Reunião Brasileira sobre a Formação do Nutricionista ${ }^{9}$, a qual recomendou que a revisão do currículo mínimo dos cursos de graduação em Nutrição atendesse à "atual realidade brasileira". Realidade colocada comoadodesenvolvimento técnico e científico, "que vem se processando em ritmo mais acelerado, ampliando assim, o campo de conhecimento que o nutricionista tem por obrigação dominar" (Associação..., 1991).

As reuniões da CEPANDAL continuaram insistindo nas recomendações curriculares. A primeira reunião, realizada em 1973, foi a mais significativa delas em relação às recomendações quanto ao ensino de Nutrição, acrescentando mais uma área de estudo, a "Multidisciplinar", às cinco estabelecidas em 1966. Essa nova área de estudo era constituída por matérias optativas e obrigatórias não previstas anteriormente, com a finalidade de proporcionar maior flexibilidade aos cursos. Distribuíram-se os conteúdos por setores do conhecimento, segundo proporcionalidade na grade curricular. Foram criadas também normas em relação à elaboração do plano de estudos e metodologia de ensino, estabelecimento de critérios de avaliação, seleção de pessoal docente e proporção professor/ aluno (Organización..., 1977).

Na década de setenta, a partir do pressuposto de que a solução dos problemas nutricionais dependia da formação e capacitação de pessoal especializado em quantidade e qualidade adequadas, a segunda reunião da CEPANDAL, realizada em 1974, não apresentou avanços quanto ao ensino de Nutrição. Trouxe, entretanto, a "Política de Formação e Capacitação de Pessoal em Nutrição", a qual recomendava para a efetivação da participação do nutricionista-dietista na equipe de saúde, a realização de um estudo acerca dos recursos humanos e institucionais necessários em Nutrição e Dietética a fim de solucionar os problemas de Alimentação e Nutrição, em cada país, de acordo com as metas do "Plano Decenal de Saúde para as Américas 1971-1980". Considerava a falta de conhecimento em Nutrição pelos demais profissionais da área da saúde, como um fator limitante ao êxito da atuação do nutricionista-dietista.

Em 1976, durante o VIII Congresso Brasileiro de Nutricionistas e V Congresso Brasileiro de Nutrição (CONBRAN), foram elaboradas várias recomendações quanto ao ensino de Nutrição, destacando-se as de que fossem obedecidos o Currículo Mínimo estabelecido em 1974, pelo Conselho Federal de Educação (CFE), e as recomendações da CEPANDAL-73 (Associação..., 1991). A Resolução n.6 de 23/12/74 do CFE, preconizava uma carga horária mínima de $2280 \mathrm{~h}$, que deveria ser integralizada em um tempo mínimo de três e máximo de seis anos, com duração média de quatro anos, incluindo atividades e trabalhos de campo com um mínimo de 300h de estágios supervisionados.

A terceira reunião da CEPANDAL, realizada em 1977, nada acrescentou às recomendações anteriores relativamente à definição do perfil profissional e ao currículo de formação de nutricionistas. Definiu-se nela o papel futuro da comissão, em torno da identificação e análise das funções do nutricionistadietista em seus vários campos de atuação e da revisão dos planos de estudos e programas de ensino, além da promoção e divulgação de estudos sobre a formação de nutricionistas-dietistas (Organización..., 1979).

$\mathrm{Na}$ verdade, as recomendações da CEPANDAL-73 constituem um parâmetro quantitativo que possibilita a análise da dosagem da carga horária no currículo por área de conhecimento e setor de estudo. Com isso, privilegiam as dimensões formais do currículo, ou seja, a carga horária. Assemelham-se a guias curriculares, fornecendo a distribuição da carga horária por áreas do conhecimento e setores de estudo, além da sugestão de disciplinas e conteúdos. Ou seja, especificam as propostas e diretrizes de ensino dentro de uma perspectiva de cunho tecnicista, sendo omissas quanto ao fazer pedagógico e à metodologia de ensino.

\section{Segundo momento: identificação, quantificação e} discussão dos problemas

No final da década de setenta, com o esvaziamento das reuniões latino-americanas acerca da formação do nutricionista, observa-se no Brasil, a

(9) Em 1972, durante o "VI Congresso Brasileiro de Nutricionistas" e III CONBRAN, realizados em São Paulo (Associação..., 1991 p. 343 ). 
emergência de estudos e eventos que discutiram a formação profissional, demonstrando o início do reconhecimento de que as mudanças ocorridas na sociedade transformavam e exigiam o repensar da profissão. Para Ypiranga (1991a) "os anos 1980s foram marcados pela 'reflexão da formação profissional do nutricionista', como projeção, é claro, dos movimentos da sociedade brasileira como um todo, característica desta década”.

Esse momento pode ser caracterizado inicialmente como o de identificação dos problemas. Nele aconteceu o acompanhamento da formação acadêmica do nutricionista através de diagnósticos nacionais dos cursos de Nutrição e da quantificação, cujos resultados foram discutidos em eventos oficiais. É o período em que apareceu no Brasil a preocupação com a avaliação dos cursos de Nutrição.

Em 1975 ocorreu o I Seminário Brasileiro dos Cursos de Graduação em Nutrição, no qual foram apresentados os resultados do I Diagnóstico dos Cursos de Nutrição. Como resultado desse evento, surgiu a recomendação de que fosse incrementada a formação do nutricionista, através do aumento do número de cursos existentes (Associação..., 1991).

O II Diagnóstico Nacional dos Cursos de Nutrição aconteceu em 1981. Dentre seus principais objetivos incluiam-se os de oferecer subsídios para a política de capacitação do nutricionista e identificar estratégias de articulação das Instituições de Ensino Superior com a prática profissional em Nutrição. Para isso foi realizado o levantamento e a análise dos dados referentes aos cursos de Nutrição, discutindo-se a sua expansão, as características do corpo docente e a composição do currículo vigente (Ypiranga, 1991a). De acordo com a Associação... (1992), pretendia-se com este evento, "um processo de acompanhamento da formação acadêmica".

A discussão dos resultados desse diagnóstico, deu-se em 1982, durante o I Seminário Nacional de Avaliação do Ensino de Nutrição, evento considerado como o grande feito da década de oitenta em relação à profissão: "a parada para a reflexão - rever os conceitos, repensar a atuação, rever os conteúdos, para formar o nutricionista do ano 2000 útil ao Brasil." Considerase que a partir daí "abriram-se caminhos para a discussão e para o pensar a formação, os objetivos, o para que do nutricionista" (Associação...,1991). Ypiranga (1996) assinala inclusive que a reflexão sobre a formação do nutricionista brasileiro foi "desencadeada nacionalmente, pela discussão dos resultados do II Diagnóstico dos Cursos de Nutrição...".

A análise sobre os aspectos conceituais, estruturais e metodológicos dos cursos de Nutrição realizada nessa ocasião, levou à constatação de que a expectativa de formação centrava-se no profissional generalista. O desejo generalizado de reformular a formação em Nutrição, entretanto, ficou evidenciado pelo descontentamento expresso com o currículo adotado pelos cursos e principalmente pela detecção de um "hiato entre o biológico e o social" e com "o descompasso entre a teoria e a prática". Percebia-se que, apesar de já se encontrarem referências à "visão social", a estrutura curricular não condizia com essa perspectiva (Associação..., 1992). A análise do currículo demonstrava o predomínio de disciplinas das áreas "Ciências Básicas" e "Multidisciplinar" e a baixa proporção das disciplinas relativas à compreensão do social, como "Educação, Ciências Sócio-Econômicas e Saúde Pública, levando, assim, a um hiato na articulação do biológico com o social" (Brasil..., 1983).

Assim, foram elaboradas recomendações visando à reorganização da formação, relacionadas aos objetivos, expectativas, compromissos e composição curriculares e às disciplinas do ciclo profissional. Enfatizaram-se nelas, o caráter generalista da formação, a integração teoria-prática, a necessidade do desenvolvimento da percepção crítica por parte do aluno, além da necessidade de articulação dos conhecimentos biológico, econômico, político e social dentro das disciplinas e do curso como um todo. Continuaram, por outro lado, as recomendações acerca dos aspectos formais do currículo, ou seja, da necessidade que a carga horária dos cursos fosse revista, tentando-se adequá-la à CEPANDAL/73 (Brasil..., 1983).

Após esse momento de debate, a formação continua em pauta nos eventos da categoria, na forma de propostas administrativas. Entre elas, a da criação da "Comissão Permanente de Ensino da Federação Brasileira de Nutrição (FEBRAN)", criada durante o IX Congresso Brasileiro de Nutricionistas e VI CONBRAN, realizados em 1982, em Brasília, com a incumbência da elaboração de "um projeto nacional de investigaçãosobre operfil profissional donutricionista" (Associação..., 1991). 
A II Reunião Brasileira Sobre a Formação do Nutricionista, promovida pela FEBRAN, em 1985, durante o X CONBRAN, recomendou a realização de um levantamento entre os cursos de Nutrição, a fim de se verificarem as mudanças ocorridas a partir dos resultados do Diagnóstico de 1981 e do Seminário Nacional de 1982 (Associação..., 1991). Ocorreu nesse evento, reunião com participação das entidades de classe: Conselho Federal de Nutricionistas, Conselhos Regionais de Nutricionistas, Associações Profissionais e Sindicatos, quando foi considerada necessária uma discussão nacional sobre assuntos referentes a categoria profissional dos nutricionistas. Surgiu, então, a proposta de realização do I Encontro Nacional de Entidades de Nutricionistas (I ENEN), ocorrido em 1986. Encontravam-se em pauta naquela ocasião, temas relacionados ao perfil profissional e ao mercado de trabalho, dentre outros de interesse dos nutricionistas, como piso salarial e jornada de trabalho (Associação..., 1991).

O referido evento foi considerado como um avanço na mobilização da categoria dos nutricionistas, pelo fato de ter encaminhado a discussão profissional dentro de uma conotação político-social, bem como por ter favorecido a reflexão sobre a prática profissional. Concluiu-se pela necessidade de redefinição da formação acadêmica, devido à sua relação com a prática do nutricionista, percebida como "...de manutenção e reprodução das relações sociais vigentes, isto é, atender aos interesses da classe dominante" (Encontro..., 1986).

Outro momento importante no cenário das discussões sobre a formação do nutricionista aconteceu em 1987, com a realização do Seminário: Formação em Nutrição no Brasil: ênfase na Graduação e ênfase na Pós-Graduação, em que ocorreu o prosseguimento da fase de diagnóstico e discussão do ensino de Nutrição. Na verdade, "pretendia-se trazer soluções aos problemas já detectados e ainda persistentes, não acessíveis através da discussão de matrizes curriculares, simplesmente" (Federação..., 1989).

Foram estudadas naquele evento as "condições do currículo de graduação em Nutrição", ou seja, os currículos dos cursos brasileiros, tendo como parâmetro as recomendações da CEPANDAL/73 (Cunha \& Gil, 1989). Foi realizada também uma atualização dos dados do Diagnóstico de 1981 e verificou-se que os currículos estudados em 1987, pouco se diferenciavam daqueles de 1981/1982, e inclusive, que "frente às recomendações da CEPANDAL, as distorções aumentaram" (Federação..., 1989). Procurou-se, concomitantemente, o aprofundamento da discussão acerca do perfil profissional do nutricionista, quando se buscou a identificação de seu objeto de trabalho. $\mathrm{O}$ avanço se deu teoricamente, na explicitação do objetivo de formar um nutricionista comprometido com as necessidades nutricionais da população brasileira. Foram obtidas, então, as várias definições pretendidas: do profissional que se almejava formar frente às necessidades da população brasileira, do objeto de trabalho do nutricionista, das áreas de atuação profissional e das ações desenvolvidas pelo nutricionista (Federação..., 1989).

Em 1988, o II Encontro Nacional de Entidades de Nutricionistas (II ENEN), continuou o debate sobre o perfil profissional e o mercado de trabalho do nutricionista. A preocupação central, naquele momento, residia na especificidade da ação profissional, ou seja, na definição das atribuições específicas do nutricionista, como busca de justificativas para a existência do profissional.

O que se pode depreender da análise das reuniões analisadas, é que apesar da relevância de algumas questões para a resolução de graves problemas no interior dos cursos de graduação em Nutrição, elas apresentaram uma certa tendência em relação ao tecnicismo. Apesar da determinação em nível de discurso, de formar um profissional "com desenvolvimento amplo da percepção crítica da realidade"(Ypiranga, 1991a), não foram preconizadas estratégias para a consecução desse objetivo.

\section{Terceiro momento: a década de noventa}

A CEPANDAL ficou praticamente desativada durante toda a década de oitenta e voltou à cena em sua quarta reunião, em 1991, após um período de quatorze anos, com sua justificativa na necessidade de atualização dos dados referentes aos cursos de Nutrição da América Latina.

O tema "A formação atual do nutricionistadietista na América Latina e sua projeção para o ano 2.000 " foi o que direcionou o encontro, do qual participaram os países latino-americanos que oferecem cursos de Nutrição. A importância dessa reunião residiu no que se pode perceber através dela: os eixos 
temáticos tratados, reveladores da real preocupação da CEPANDAL no decorrer dos anos e na década de noventa, permanecem os mesmos.

Os debates situaram-se em torno dos problemas atuais na formação do nutricionista-dietista, das estratégias para dar solução a esses problemas e das recomendações que poderiam fortalecer a formação e projeção desse profissional. Apareceu a premência da redefinição da identidade do nutricionista do ano 2000, de acordo com o momento atual de cada país e dos países da América Latina em seu conjunto, assim como seu espaço de ação e sua inter-relação com outras profissões. Em outras palavras, a preocupação central permaneceu na especificidade das competências do nutricionista e na análise da situação atual de formação do nutricionista - dietista na América Latina (Instituto..., 1992).

A principal conclusão do evento, segundo Ypiranga (1991b), foi a de que "há um descompasso entre teoria e prática na formação do profissional nutricionista. Verifica-se, portanto, que a mesma conclusão das discussões ocorridas na década de oitenta, no Brasil, foi evidenciada no início dos anos noventas na América Latina.

As conclusões e recomendações da quarta CEPANDAL apontaram a necessidade de elaboração de um "Plano de Desenvolvimento Integral", com eixo na avaliação sistemática dos currículos, adequando-os à necessidades de cada país. Tal plano, quando implementado, deverá contemplar a seleção de metodologias que favoreçam a participação, a análise crítica e a capacidade criativa dos estudantes, a participação das instituições prestadoras de serviços, participação que assegure a integração docente-assistencial, as ações de educação contínua para docentes e profissionais dos serviços e o papel a ser desempenhado pelos diferentes grupos de Alimentação e Nutrição (Organización..., 1992).

Mais uma vez, foram colocadas as "recomendações", o "deve ser", e, apesar de teoricamente voltadas para as necessidades de cada país, não indicaram um avanço/desenvolvimento na perspectiva teórico-metodológica da análise do trabalho realizado pelo profissional nutricionista, confirmando o contínuo distanciamento da temática mais abrangente do trabalho como categoria de análise.

\section{OS EIXOS TEMÁTICOS}

Os momentos estudados acerca da formação do nutricionista encontram-se permeados por eixos temáticos que os perpassam: o perfil profissional eo currículo.

O perfil profissional

Os eventos latino-americanos patrocinados pela OPS/OMS sempre se preocuparam com a definição do perfil profissional.

Na década de sessenta, fase em que o alvo principal das reuniões sobre a formação se encontrava no esclarecimento das atribuições/funções do profissional, recomendava-se que os nutricionistas fossem formados como profissionais polivalentes, ou seja, com habilidade para atuar no campo hospitalar, da saúde pública e em educação e ensino (Associação..., 1991).

Em 1966, na I Conferência de Adestramento, a definição de nutricionista-dietista era "un profesional de nível universitario, calificado por formación y experiencia para actuar en los servicios de salud pública y asistencia médica, con el fin de mejorar la nutrición humana, esencial para el mantenimiento del más alto nível de salud" (Organización..., 1977).

Enfatizaram-se, naquele encontro, as atividades preventivas e de fomento à saúde nos serviços de Saúde Pública, a administração de Serviços de Alimentação e o tratamento dietético dos enfermos.

A II Conferência de Adestramento, em 1973, reconheceu a atuação do nutricionista-dietista como integrante de uma equipe em diferentes níveis de setores públicos e privados, segundo as necessidades e prioridades de cada país: saúde, educação, agricultura, indústria e comércio, economia e administração. Suas funções seriam: planejamento de dietas e atenção dietética, administração de programas de Nutrição e Dietética, educação e treinamento, investigação, assessoria e consultoria (Organización..., 1977).

Na década de oitenta, as discussões sobre o perfil profissional intensificaram-se e, no II Seminário de Avaliação, em 1987, ficou mais clara a percepção do tipo de profissional que se queria formar: " $O$ NUTRICIONISTA é um profissional de saúde, com formação ou caráter generalista e com uma percepção crítica da realidade (consciência social, econômica, 
cultural e política), dentro de áreas próprias de atuação" (Federação..., 1989).

Para uma melhor definição do perfil profissional, foram elaboradas várias aproximações, entre elas a relacionada com o objeto de trabalho donutricionista, que ficou mais nítido: "oalimentoe/ou a alimentação em sua relação com o homem" (Federação..., 1989).

O II ENEN, em 1988, definiu o nutricionista como um "...profissional generalista, de saúde, de nível superior, com formação em Nutrição e Dietética, que desenvolve uma visão crítica da realidade e comprometido com as transformações da sociedade".

O objeto de ação do nutricionista definido nesse evento foi "a saúde do homem, inserido numa forma de organização social, tendo como seu eixo de formação o homem e o alimento no seu contexto social" (Associação..., 1991).

A despeito das definições elaboradas teoricamente para esclarecer quem é o nutricionista, o perfil profissional permaneceu com baixa visibilidade, ou seja, sem representação social clara. A tentativa de delimitação do perfil em nível teórico, na verdade, não se concretizou, pois o perfil profissional real é aquele que vem sendo construído no decorrer do tempo, através da interação entre a formação acadêmica, o mercado de trabalho e a atuação desenvolvida pelo profissional em um determinado contexto socioeconômico.

\section{Currículo}

Uma característica desse eixo temático é a discussão acerca do enfoque dado ao ensino de Nutrição, na qual surge a polarização entre o biológico e o social nos currículos, que na verdade significa a discussão acerca da formação técnica e política do nutricionista.

A ênfase do enfoque biologista aparece desde o início da formação e pode ser notada como uma das orientações em relação ao currículo no Brasil, recomendadas no IV Congresso Brasileiro de Nutricionistas, em 1967:

"A formação deve ser orientada considerando a importância das características do meio, especialmente as tradições e os costumes, incutindo desde cedo a noção de que a doença só acontece pela interação de vários fatores repre- sentados, pelo paciente, pelo agente etiológico e pelo ambiente" (Associação..., 1991, p. 139).

$\mathrm{Na}$ década de oitenta, os eventos reafirmavam o predomínio do biologicismo:

"A formação do profissional na área de nutrição vem sendo feita a partir de uma visão do mundo fragmentadora e biologicista que ao abordar a saúde e a doença como processos naturais e indi-viduais, não forma um profissional realmente comprometido com uma prática voltada para a transformação dos processos sociais e biológicos que determinam a fome e a desnutrição" (Associação..., 1991, p.359).

Em 1988, no II ENEN, constatou-se e denunciou-se que:

"A prática atual do Nutricionista é de manutenção e reprodução das relações sociais vigentes; e é considerado também, que o perfil desejadofica atrelado à consciência amadurecida da real posição do nutricionista e da Nutrição no país" (Associação..., 1991).

Verifica-se, portanto, a percepção da atuação do profissional nutricionista no processo de constituição da sociedade capitalista brasileira. Constata-se inclusive que o currículo dos cursos de Nutrição têm contribuído para a manutenção das relações sociais vigentes (Bosi, 1988; Santos, 1988; Barreto, 1992).

\section{REPENSANDO O SIGNIFICADO DOS ESTUDOS E EVENTOS} SOBRE A FORMAÇÃO DO NUTRICIONISTA

A importância da revisita realizada por este trabalho aos estudos e eventos sobre a formação do nutricionista, reside no fato de que neles ocorreram o debate e a construção de propostas visando ao aprimoramento da formação profissional. Essas propostas não surgiram ao acaso, mas foram originadas das experiências dos indivíduos com o mundo concreto, das relações dos homens entre si e deles com as coisas. Cada passo ocorrido na evolução da formação do nutricionista, portanto, não deve ser entendido como uma etapa linear, mas como o resultado de processos contraditórios, de avanços e retrocessos, de lutas e interesses em jogo.

O repensar da trajetória do nutricionista a partir dos estudos e eventos aqui analisados traz uma 
constatação: os momentos latino-americanos e brasileiros de discussão sobre o perfil profissional e sobre o currículo são desenvolvidos a partir do "deve ser". A formação acontece de determinada forma e deve ser reformulada, modificada, daí surgindo as freqüentes "recomendações". No momento inicial dos eventos enumeram-se os problemas, no momento das conclusões enumeram-se as soluções, ou seja, as recomendações. As publicações da OPS/OMS sobre o profissional nutricionista vêem os problemas como apenas relação de causa e efeito. Parecem deixar de lado o papel do profissional na resolução dos problemas nutricionais e se isentam de efetuar uma análise mais ampla dos elementos que influenciam na dinâmica da profissão.

Pode-se dizer, inclusive, que os estudos promovidos para efetuar os chamados diagnósticos nacionais e para discutir o perfil profissional do nutricionista, na realidade, apenas buscaram funcionalizar a orientação dos planos de ensino a uma série de demandas que supostamente surgiam das necessidades de desenvolvimento nacional, de uma política de ciência e tecnologia e de uma racionalidade entre o perfil existente, os conhecimentos técnico-profissionais e os planos de estudo.

Uma constatação sempre presente nos eventos e estudos sobre a formação do nutricionista é a da existência de um "hiato entre o biológico e o social" nos currículos, quando as instituições formadoras e as associações de classe analisaram a formação e detectaram as discrepâncias entre o perfil dos egressos e as transformações ocorridas na sociedade, e advogaram a necessidade do compromisso do profissional com a transformação dessa sociedade. $\mathrm{O}$ resgate histórico dos estudos sobre a formação demonstra que a falta de mecanismos concretos para a articulação dos conhecimentos biológicos e sociais é limitada pela deficiência de uma análise crítica da realidade da formação, da prática profissional e da totalidade social.

Os maiores avanços efetuados nas discussões ocorridas no Brasil aconteceram na década de oitenta, quando ficou esboçada a discussão acerca da inserção do profissional no contexto mais abrangente dos profissionais da área da saúde e do compromisso a ser assumido com a maioria da população brasileira.

Esses momentos, porém, representaram uma etapa inconclusa do processo de integração dobiológico e do social no currículo de formação de nutricionistas, quando se tentou o compromisso do nutricionista com a sociedade no plano das idéias, da intenção. Neles, os nutricionistas perseguiram o aprofundamento teórico imprescindível às discussões que poderiam levar a um salto qualitativo na formação. Contudo, tal intenção não se concretizou, porque naqueles momentos os profissionais assumiram tanto a responsabilidade pela causa, como pela solução dos problemas, em vez de buscarem a compreensão mais ampla da realidade. Não reconheceram que através apenas do seu trabalho não seria possível solucionar problemas de competência das ações multisetoriais dependentes do encaminhamento e da vontade política. Jogou-se para o nível individual, aquilo que é histórico, fruto de relações concretas da produção capitalista, entre capital e trabalhoe, assim, de antemão, a batalha estava perdida.

Embora reconhecendo idéias positivas nesses momentos, é difícil ver neles, algo além do mérito de estimular o consenso em torno de certos ideais. Atribuiu-se ao discurso difundido uma força capaz de transformar a prática, como se o discurso pudesse se tornar realidade pela própria força da evidência e pela implementação de medidas administrativas.

É necessário relacionar os fenômenos/fatos/ acontecimentos, nesse caso, o nível inadequado de saúde e nutrição da população, além de outros determinantes da qualidade de vida, com o todo com o qual se articulam, na tentativa de ultrapassar a aparência do fenômeno. Importa, portanto, buscar os nexos existentes entre a formação do nutricionista e a formação superior na área da saúde, os vínculos existentes entre o conhecimento em nutrição e o conhecimento em ciências sociais, pois, neles estão presentes a luta entre o conhecimento biológico e o social, o embate entre o técnico e o político, vivenciados não apenas pela formação em Nutrição, mas por todos os cursos da área da saúde.

Para a formação acadêmica do nutricionista existem possíveis soluções alternativas. A distribuição e a organização do conhecimento estão ligados à transformação histórica do processo de produção econômica. Não se trata de substituir um currículo por outro, uma disciplina por outra, mas de elaborar, discursivamente, a base de uma argumentação racional e fundamentada, as novas categorias do pensamento e as novas diretrizes que orientarão a formação em Nutrição. Afinal de contas, é o currículo, ou são os vários tipos de currículo presentes nos cursos, que 
ensinam ao nutricionista quem ele é. As escolhas, as seleções efetuadas nos currículos não podem ser aleatórias ou apenas utilitárias. O currículo é, nesse sentido, um recorte intencional. A formação profissional significa esforços, sacrifícios e custos de toda natureza. É necessário, portanto, que tenha um significado teórico e prático para o profissional e principalmente para os que usufruem da sua prática. Através das escolhas, das seleções efetuadas, o compromisso com a construção de uma sociedade mais justa e solidária pode desenvolver-se e consolidar-se.

\section{REFERÊNCIAS BIBLIOGRÁFICAS}

ARIZA, J. Maestria en ciencias de la salud con concentración en Nutrición. Archivos Latinoamericanos de Nutrición, Guatemala, v.42, n.3, p.8S-11S, 1992.

ASSOCIAÇÃOBRASILEIRA DENUTRIÇÃO. Histórico do nutricionista no Brasil, 1939 a 1989 : coletânea de depoimentos e documentos. São Paulo : Atheneu, 1991.444p.

ASSOCIAÇÃO BRASILEIRA DE NUTRIÇÃO. A formação do nutricionista no Brasil: sinopse de estudos e diagnósticos realizados nas três últimas décadas. Brasília, 1992.20p.

BARRETO, I. Sociedade, saúde e a formação do nutricionista. Goiânia, 1992. 303p. Dissertação (Mestrado em Educação Escolar Brasileira) - Universidade Federal de Goiás, 1992.

BAZÓ, A.L. Los trabajadores auxiliares en nutrición de salud pública. In: ORGANIZACIÓN PANAMERICANA DE LA SALUD. Formación academica de nutricionistas-dietistas en America Latina. Washington DC, 1977. p.38-42. (Publicación Científica, n340).

BOSI, M.L.M. A face oculta da nutrição: ciência e ideologia. Rio de Janeiro : UFRJ/Espaço e Tempo, 1988.220p.

BOSI, M.L.M. Profissionalização e conhecimento: a nutrição em questão. São Paulo: HUCITEC, 1996. 204p.

BOSLEY, B. Análisis del programa de estudios de las escuelas de Nutrición y Dietética de América Latina. In : ORGANIZACIÓN PANAMERICANA DE LA SALUD. Formación acadêmica de nutricionistas-dietistas en America Latina Washington DC, 1977.p.56-67.(Publicación Científica, n.340).
BRASIL. Ministério da Educação e Cultura. Secretaria do Ensino Superior. Os cursos de Nutrição no Brasil: evolução, corpo docente e currículo. Brasília, 1983. 280p. (Série Cadernos das Ciências da Saúde, n.6).

BRASIL. Ministério da Saúde. Formação superior em saúde: tendências da graduação no período 1985/ 1991. Cadernos de Recursos Humanos em Saúde, Brasília, v.1, n.2,p.1-183, 1993.

CASTELLANOS, B.E.P., SHIMA, H., BERTOLOZZI, M.R.,EGRY,E. Desafios da enfermagem brasileira na contexto da América Latina para a década de 90. Saúde em Debate, Londrina, n.34, p.72-76, março, 1992.

CUNHA, D.T.O., GIL, M.F. Condições do currículo de graduação em Nutrição. In: SEMINÁRIO NACIONAL SOBRE O ENSINO DE NUTRIÇÃO, 2., 1989, Goiânia. Anais... Goiânia: FEBRAN, 1989. p.37-112.

ENCONTRO NACIONAL DE ENTIDADES DE NUTRICIONISTAS, 1. Relatório final. Brasília, 1986. $16 \mathrm{p}$.

FEDERAÇÃO BRASILEIRA DE NUTRIÇÃO. II Seminário Nacional Sobre o Ensino de Nutrição, Goiânia, 1989.214 p.

INFANTE, N.B., ALVAREZ, L., LANDAZABAL, G. La presencia de las ciencias sociales en la formación del profesional de enfermaria. Educación Médica y Salud. Washington DC, v. 26, n.1, p.82-105, 1992.

INSTITUTO DE NUTRICIÓN DE CENTROAMERICA Y PANAMÁ. La formación actual do nutricionistadietista en América Latina y su proyección hacia el año 2.000. Archivos Latinoamericanos de Nutrición, Guatemala, v.42, n.25, p.45-47, 1992.

L'ABBATE, S. As políticas de alimentação e nutrição no Brasil. I. período 1940 a 1964. Revista de Nutrição da PUCCAMP, Campinas, v.1, n.2, p.87-138, 1988.

MEDICI, C.M., MACHADO, M.E., NOGUEIRA, R.P., GIRARDI, S.N. El mercado de trabajo en salud: aspectos teóricos, conceptuales y metodologicos. Educación Médica y Salud, Washington DC, v.25, n.1, p.1-14, 1991.

NUNES, S. Nutricionista: um profissional em busca de seu papel social. São Paulo, 1992. 149p. Dissertação (Mestrado em História e Filosofia da Educação) Pontifícia Universidade Católica de São Paulo, 1992.

ORGANIZACIÓN PANAMERICANA DE LA SALUD. Formación academica de nutricionistas-dietistas en America Latina. Washington DC, 1977. 118p. (Publicación Científica, n.340). 
ORGANIZACIÓN PANAMERICANA DE LA SALUD. Formación academica de nutricionistas-dietistas en America Latina. Washington DC, 1979. 25p. (Publicación Científica, n.340-A).

ORGANIZACIÓN PANAMERICANA DE LA SALUD. Reunión de la Comissión de Estudios Sobre Programas Acadêmicos en Nutrición y Dietética. Boletin de la Oficina Sanitaria Panamericana, Washington DC, v.12, n.4, p.373, 1992.

PRADO, S.D. Autonomia: tentadora e reificada. Estudo sobre os nutricionistas dos centros municipais de saúde do Rio de Janeiro. Rio de Janeiro, 1993. 145p. Dissertação (Mestrado em Saúde Püblica) - Escola Nacional de Saúde Pública, Fundação Oswaldo Cruz, 1993.

SANTANA, J.P., GIRARDI, S.N. Recursos humanos em saúde: reptos atuais. Educación Médica y Salud, Washington DC, v.27, n.3, p.341-356, 1993.

SANTOS, S.M.C. Nutricionista e sociedade brasileira: elementos para abordagem histórico-social da profissão. Salvador, 1988. 240p. Dissertação (Mestrado em Saúde Comunitária) - Universidade Federal da Bahia, 1988.

VIANA, S.V. Nutrição, trabalho e sociedade. São Paulo: HUCITEC, 1996. 167p.
YPIRANGA, L., GIL, M.F. Formação profissional do nutricionista: por que mudar? In: SEMINÁRIO NACIONAL SOBRE ENSINO DE NUTRIÇÃO, 2., 1989. Goiânia. Anais... Goiânia : FEBRAN, 1989. p.19-36.

YPIRANGA, L. O nutricionista no Brasil: contribuição para a análise e projeção da formação do nutricionistadietista na América Latina. In: REUNIÃO DA COMISSÃO DEESTUDOS SOBRE PROGRAMAS ACADÊMICOS EM NUTRIÇÃO EDIETÉTICADA AMÉRICA LATINA, 4., 1991, San Juan, Porto Rico. Anais... San Juan, Porto Rico : CEPANDAL, 1991a. $15 \mathrm{p}$.

YPIRANGA, L. Relatório apresentado à ASBRAN e aos cursos de Nutrição do Brasil. [s.1. : s.n.] 1991b. 7p. Informe sobre a participação brasileira no IV Reunião da Comissão de Estudos sobre Programas Acadêmicos em Nutrição e Dietética da América Latina, San Juan, Porto Rico.

YPIRANGA, L. A formação e o perfil profissional do nutricionista. Rio de Janeiro, 1996. 20p. Conferência proferida no Fórum de Debates: A Nutrição e o nutricionista em questão. UFRJ/CRN-4.

Recebido para publicação em 13 de junho de 1997 e aceito em 11 de maio de 1998. 